\title{
The Challenge of Managing the "Third-Space" in Total Knee Arthroplasty: Review of Current Concepts
}

\author{
Auro Caraffa ${ }^{1,2}$ \\ 1 Service of Orthopedics and Trauma Surgery, Santa Maria della \\ Misericordia Hospital, Perugia, Italy \\ ${ }^{2}$ Department of Orthopedics and Traumatology, University of \\ Perugia, Perugia, Italy \\ 3 Service of Orthopedics and Traumatology, Azienda Ospedaliera \\ Regionale San Carlo, Potenza, Italy \\ ${ }^{4}$ I.R.T.A.L. Istituto di Ricerca Traslazionale Apparato Locomotore, \\ Nicola's Foundation, Arezzo, Italy
}

Pierluigi Antinolfi ${ }^{1}$ Francesco Manfreda ${ }^{2} \quad$ Giacomo Placella $^{3} \quad$ Julien Teodori ${ }^{2} \quad$ Giuliano Cerulli ${ }^{4}$

Joints 2018;6:204-210.
Address for correspondence Pierluigi Antinolfi, PhD, MD, Service of Orthopedics and Trauma Surgery, Santa Maria della Misericordia Hospital, Piazza Menghini, 1, 06129 Perugia, Italy (e-mail: pantinolfi@gmail.com).

\begin{abstract}
Keywords

- total knee arthroplasty

- patella

- resurfacing

- patelloplasty

- patellofemoral joint

Total knee arthroplasty (TKA) is the best treatment for advanced knee osteoarthritis and it has proven to be durable and effective. Anterior knee pain (AKP) is still one of the most frequent complications after TKA, but sometimes no recognized macroscopic causes can be found. The correct treatment of patella is considered the key for a proper management of AKP. The inclusion of patellar resurfacing during TKA has been described as a potential method for the reduction of AKP. After surgeons started to resurface the patella, new complications emerged, such as component failure, instability, fracture, tendon rupture, and soft tissue impingement. Patelloplasty has been proposed as a good alternative to resurfacing but whether or not to resurface the patella is still a controversial topic in the literature. Therefore, patellofemoral joint is a complex critical aspect in TKA and choosing between the several options of treatment of patella could not be sufficient. In this review, evidence-based studies do not succeed in resolving this difficult argument. The accurate management of the so-called "third space" should include an accurate assessment of cartilage layers, balance of soft tissue, preoperative anterior tracking, and positioning of the femoral and tibial components. In fact, the selection of suitable implants and adherence to proper surgical technique are the fundamental principles for the success of TKA.
\end{abstract}

\section{Introduction}

The patellofemoral (PF) joint (PFJ) is involved in over $45 \%$ of cases of knee osteoarthritis (OA), independently or concurrent with OA in the other compartments. ${ }^{1}$ Despite its incidence, few papers in the literature have focused on it. Patellar disorders are strictly linked to anterior knee pain (AKP) and sometimes it can be traced back to malalignment of the extensor mechanism. $^{2}$ PF malalignments seem to have several predisposing

received

January 31, 2018

accepted after revision

October 7, 2018

published online

December 10, 2018 intrinsic factors, such as neural inflammation, altered proprioception, patellar tendinitis, Osgood-Schlatter disease, coronal knee malalignment, and joint hypermobility. ${ }^{3-7}$ There are also some others causes of AKP that are not related to malalignment, such as inflammatory disease, tumors, infections, stress fractures, fat pad inflammations, and psychological causes. ${ }^{8,9}$

Total knee arthroplasty (TKA) is the most effective treatment for advanced knee OA. The intervention does not always include a resurfacing of the patella, even if PFJ is frequently
Copyright $\odot 2018$ Georg Thieme Verlag License terms KG Stuttgart · New York

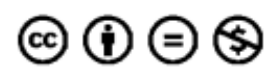


involved. PFJ is a critical aspect of kinetic features of the implant design in TKAs and is supposed that implant kinematics contributes to PF complications. A successful TKA generally is able to increase knee flexion angle, thus enhancing the PF contact and pressing forces. ${ }^{10}$

Long-term changes for nonresurfaced patella have been described. Laughlin et al demonstrated how the lateral tilt increases over time. ${ }^{11}$ Shih et al showed that in patients with long-term follow-up the patellar tracking and the PFJ remained normal in $60 \%$ of the TKAs, but progressive degenerative changes and patellar maltracking are common radiographic findings. Retention of the native patella is associated with progressive degeneration of the lateral patellar facet in $85 \%$ of cases. $^{12}$

Patients with preoperative patellar maltracking could be considered at risk of developing these abnormalities and clinical symptoms. Indeed, leaving the native patella is related to a high incidence of AKP, up to $47 \%{ }^{13,14}$ For this reason, some authors recommend routinely resurfacing the patella. ${ }^{15,16}$

Nevertheless, some studies showed that patella complications in TKA are more frequent in the resurfaced group than in nonresurfaced one. ${ }^{17-19}$ Some others suggested a selective decision based on factors such as preoperative AKP, evaluation of patellar thickness, severity of OA in the third compartment, and the experience of the surgeons. ${ }^{20,21}$ Therefore, during surgery, surgeons that do not routinely resurface the patella should consider several issues, including the severity of OA, knee alignment, PF tracking, implant design, and position of the components.

If the surgeon decides to retain the native patella, several options could be chosen to reduce the rate of AKP and improve the outcomes. Options that have been described include patelloplasty, denervation, and circumferential resection of the osteophytes. Patelloplasty has been defined as the surgical options aiming at the improvement of the congruency between the patella and the trochlea, conducting a real reshaping of the patella. ${ }^{22}$

Despite the excellent records about the long-term outcome of TKA, there remains controversy about the correct management of the PFJ.

\section{Patellar Resurfacing}

In 1955, McKeever tried to reduce pain in PFJ OA by patella resurfacing as an alternative to patellectomy or debridement. ${ }^{2}$ Even though TKA has shown good results almost since its creation, in the 1970s many physicians identified AKP as a frequent complication of TKA. Since then, the implants included the patellar component. This choice resulted in reduction of incidence of AKP, but despite this, complications related to resurfacing started to emerge.

Several designs and materials have been used for patellar resurfacing. At the beginning, all-polyethylene patellar components were used, but they presented with early deformation and accounted for almost 50\% of all TKA revisions. ${ }^{23}$ Some years later, a metal backing was incorporated into the design to give load transfer to the patellar bone and to allow cementless fixations using a porous metal surface. Unfortu- nately, new complications arose related to the shearing forces between the polyethylene surface and the metal backing under eccentric loads. ${ }^{24}$ One of the most frequent complications, the polyethylene wear, resulted in exposure of the metal backing leading to metal-on-metal contacts. Loosening and migration became frequent, leading to exposition of the femoral metal to the patellar bone. Several studies conducted onto the metal-backed patella reported 5 to $33 \%$ failure rate. ${ }^{25,26}$ Later, engineers tried to modify the polyethylene dome shapes to normalize the contact forces, thus improving polyethylene wear patterns. ${ }^{27}$ The introduction of a low-contact-stress press-fit metal-backed rotating patella increased the congruity of the PFJ. These innovative designs led to the reduction of contact pressure, which resulted in fewer complications. $^{28}$

Actually, modern prostheses incorporate an all-polyethylene patellar component with pegs (from 1 to 3 ) and cemented fixation, reducing the high risk of failure with the cementless metal-backed implants.

The implants are available to the surgeons in the range of 8 - to $10-\mathrm{mm}$ thickness. A caliber should be used to measure the central patellar thickness, with the aim of maintaining the anatomical thickness. A residual bone thickness of approximately $15 \mathrm{~mm}$ is required. ${ }^{29}$ The patella resection is performed with the aim of being flat. The implant is placed and generally cemented, because, as we have previously said, complications rate may decrease with cement. Medial placement of the implant improves patellar tracking when compared with central placement. ${ }^{30}$ Only if the patella tracks laterally or lifts off medially, a lateral patellar retinacular release should be performed. Some authors describe an additional lateral facetectomy, proper of patelloplasty, and it can be performed when a malaligned patella is addressed. Open partial lateral patellar facetectomy has been shown to improve function but with poor correlation with radiological findings. ${ }^{31}$

Several complications can occur following patellar resurfacing. Instability is probably the first one, requiring revision surgery in about 0.5 to $0.8 \%$ cases. Factors that could contribute to patellar instability include malposition of the components, soft tissue imbalance, excessive femoral component size, and inadequate patellar resection. ${ }^{32,33}$ Treatments for instability are component revision, proximal and distal realignment of the soft tissue, and osteotomy of the tibial tubercle. The most dangerous complication is patellar fracture $\left(0.05-8.5 \%\right.$ of TKA cases). ${ }^{34-36}$ Decreased bony thickness combined with osteopenia, avascularity, trauma, fatigue, and stress can generate this kind of adverse event, whose risk increases when lateral retinaculum release is simultaneously performed. ${ }^{37}$

Fractures may occur during surgery too: an extremely thin patella is at higher risk of fracture due to the high mechanical pressures. Patellar fractures are generally treated with a conservative approach, especially when an implant is not loose and the extensor mechanism is not disrupted, whereas surgical options include open reduction with internal fixation, excision of fracture fragments, and patellectomy. ${ }^{38,39}$ Another complication is wearing of the patellar component (incidence ranging between 5 and 11\%). ${ }^{23}$ Factors that can be 
associated to this complication are maltracking and abnormal contact force. Maltracking is able to induce component loosening in 0.6 to $1.3 \%$ of cases, as well as traumas. ${ }^{40}$ Softtissue impingement, the so-called patellar clunk syndrome, results from the formation of a fibrous nodule over the patella proximal pole and is strictly associated with posterior stabilized design. ${ }^{38}$ Generally, it can be treated through an arthroscopic or open resection. The patellar ligament rupture $(0.22-0.55 \%)^{41}$ can be due to excessive dissection, knee manipulation, and trauma. Either staple fixation or grafts can be used in treating acute ruptures, but with poor outcomes. ${ }^{42}$

The advent of modern prosthetic designs with better PF congruence, smoother patellar tracking, and superior patellar fixation, has led toward fewer patellar complications. Recent studies have reported lower PF complication. ${ }^{43}$

Some authors have proposed algorithms to assess the ideal candidate to patella resurfacing. Bourne and Burnett ${ }^{44}$ formulated five criteria for choosing the resurfacing option: severe PF OA, poor tracking, inflammatory arthritis, obesity, and age over 60 . Several studies have denied all these beliefs: no differences have been found between obese and nonob$\mathrm{ese}^{45}$; no correlation has been proved with severity of $\mathrm{OA}^{46}$; and studies on alignment have also considered the correlation between malalignment and necessity for a resurfacing, without a certain result. ${ }^{47}$

Some gross data derived from randomized clinical trials (RCTs) seem to support those surgeons who are used to resurface the patella. ${ }^{48}$ Anyway, some systematic reviews and meta-analysis summarized that the decision is still difficult. Pakos et $\mathrm{al}^{49}$ reviewed 10 RCTs that favored patellar resurfacing when compared with the relative risk of revision and AKP. Parvizi et $\mathrm{al}^{50}$ conducted a meta-analysis on 14 studies, which proved that there was no difference between resurfaced and un-resurfaced patellas in reoperation rate, but showed that patellar resurfacing results in the reduction of AKP and achieve better patient satisfaction. Nizard et $\mathrm{al}^{51}$ demonstrated a lower risk of reoperation for resurfaced patella with respect to un-resurfaced $(0.43$ vs. 0.71$)$. The Swedish Knee Arthroplasty Register, in 2004, reported a 10-year followup in over 30,000 patients, where secondary resurfacing was found to be the main cause for reoperation. ${ }^{52}$ In 2007, the Australian National Joint Registry reported a relative risk of reoperation in $4.7 \%$ for un-resurfaced patellas, as compared with $3.8 \%$ for resurfaced. The same registry shows no differences regarding the type of fixation of the component. ${ }^{53}$ Calvisi et $\mathrm{al}^{54}$ found that resurfacing might reduce the risk of reoperation and AKP. Patil et $\mathrm{al}^{55}$ evaluated functional scores such as the Knee Society Score (KSS), 36-Item Short Form Health Survey, and satisfaction, and found no differences during comparisons. ${ }^{55} \mathrm{Li}$ et al conducted a large review founding no differences between the two groups. ${ }^{56}$ Chen et $\mathrm{al}^{57}$ published the most recent, important, and valuable meta-analysis about this issue 4 years ago. They reviewed 14 RCTs, with homogenous parameters, with a cumulative size of over 1,700 patients. Relative risk of reoperation favored the patellar resurfacing ( 0.50 vs. 0.76 ), but no significant differences were found for AKP. Anyway, the authors revealed a higher KSS in the resurfaced group. ${ }^{57}$

\section{Patelloplasty}

Patelloplasty consists of different procedures, such as patellar decompression, lateral patellectomy, and patella reshaping, which are aimed at creating a good congruence between the patella and femur. It has the advantage of conforming to the articular facets of the patella toward a large variability of tracking surfaces. In fact, the shape of the trochlea could vary and the shape of the femoral prosthetic component can vary as well according to the implant design. $^{58}$

Reshaping of the patella has the scope of achieving a good matching between the prosthetic trochlea and the articular surface of the patella. This procedure is conducted with or without a resection of cartilage layer. ${ }^{22}$ Unfortunately, this is not a well-standardized procedure. There are no specific and worldwide-recognized steps of procedure. There is an excessive variability of gestures. Some author use to reduce the thickness of the patella to less than $20 \mathrm{~mm}$, while some other between 22 and $26 \mathrm{~mm}$. Some authors totally remove the cartilage layer, while some others leave the native one. Therefore, as there is a great variability in the procedure, a great variability could exist in outcomes as well. All these gestures are original, without a real validation in the literature.

Rate of complications is controversial due its variability in procedures. Although this is a technique characterized by rare intraoperative complications, ${ }^{59}$ there could be some postoperative ones, such as maltracking for a new patellar shape and a controversial adverse reduction of the strength of the extensor mechanism; but this topic has not yet been investigated in the literature.

The literature is still poor of relevant studies about this issue. Sun et al $^{59}$ published a retrospective study with 152 patients, divided in two groups: patelloplasty versus denervation. They found that patelloplasty was better in both relieving AKP and improving patient's satisfaction and knee function. ${ }^{59}$ Župan et $\mathrm{al}^{60}$ reported better clinical outcomes in patients with patelloplasty with respect to the simple denervation and removal of osteophytes. They found better outcomes in Knee injury and Osteoarthritis Outcome Score (KOOS) and in Oxford Knee Score, but revealed no significant differences in KSS and pain scores. They also correlated the results to postoperative patella thickness, but they found no significant correlation. The first systematic review focusing on patelloplasty in primary TKA has been conducted by Cerciello et $\mathrm{al}^{22}$ about clinical results, the comparison between patelloplasty and simple denervation and osteophytes removal revealed lower AKP in patelloplasty ( $2.9 \%$ vs. $4.6 \%$ ), as well better clinical outcomes at KOOS, KSS, and Feller patellar score. ${ }^{22,61-63}$

Though all these evidences show that patelloplasty is a safe procedure without frequent intraoperative and postoperative complication, the quality and quantity of studies are still poor.

Control groups in the studies are often lacking. In some other studies, preoperative data are missing, so comparisons are extremely difficult. 


\section{Other Alternatives}

Intraosseous hypertension is another important hypothetical cause of AKP in the third space after TKA. ${ }^{64,65}$ In degenerative pathologies of the knee, an increased intraosseous pressure is described ${ }^{66}$ This patellar hypertension, though not specifically studied yet, is reported to be associated with idiopathic AKP. ${ }^{67}$

In several experimental studies, an impaired venous drainage are linked with hypertension, especially in patients with patellar chondromalacia and OA. ${ }^{68}$ Causes for an altered venous drainage include direct compression of vascularization from fat pad, osteophytes of the superior patella, a sustained knee flexion position, chondromalacia, and OA. ${ }^{67,69,70}$

Patellar drilling has been proposed for improving impaired drainage and it could indirectly relieve AKP. The first results described after decompression by drilling via the infrapatellar fat pad reported a direct reduction of intraosseous pressure and pain relief. ${ }^{71}$

Ertürk et $\mathrm{a}^{72}$ published a trial on 49 TKAs treated with patelloplasty and decompression of the patella. They conducted the decompression drilling on the edge of the patella with the aim of not damaging the articular cartilage and drilling at vertical plane to minimize the risk of fracture. The authors reported excellent clinical results, especially for range of motion (ROM) and patellar scores. Anyway, the study did not use a control group. ${ }^{72}$

Lee et $\mathrm{al}^{67}$ compared patelloplasty to patelloplasty decompression. A $3.5-\mathrm{mm}$ drill has been used via fat pad under tissue protection in the group with decompression. The authors reported AKP in 21.3\% of the control group and in $18.5 \%$ of the study group. Higher KSS was observed in patients with decompression (78.2 vs. 71.8 ).

\section{Discussion}

The incidence of AKP is high after TKA, reported between 4 and $49 \% .{ }^{73}$ Daily activities are impaired due to this complication: they include stair climbing, cycling, and getting up from a chair. Pathogenesis of AKP is still unclear but several potential factors have been proposed to be linked.

Over time, the most studied options for the management of this complication have been the treatments of patella during a TKA.

The gross data reviewed in this article show that the patella resurfacing might reduce pain but is associated to severe complications. Moreover, some systematic reviews and meta-analysis did not succeed in finding significant differences in terms of clinical outcomes.

Unfortunately, patelloplasty is still poorly studied, even if it seems the best alternative solution to resurfacing of the patella. Systematic reviews and meta-analysis are affected by poor quality of RCTs both in the methodology and in uniformity of samples of patients and outcomes.

RCTs are generally conducted through clinical and radiographic evaluations, but few articles are available about biomechanical performances. Smith et $\mathrm{al}^{74}$ evaluated the gait pattern by a meta-analysis, showing no significant differences between resurfaced and un-resurfaced patellas. Myles et $\mathrm{al}^{75}$ used an electrogoniometer to evaluate improvements in ROM, but they found no differences between the two groups of patients.

Scientific literature lacks RCTs that focus on comparison between patella resurfacing and patelloplasty. Campbell et al ${ }^{76}$ found no significant differences in the International Knee Society and Western Ontario and McMaster Universities Osteoarthritis Index scores at 10-year follow-up. Similar uncertain results have been reported by Burnett el al. ${ }^{47} \mathrm{How}-$ ever, despite the clinical scores, patient's preference was toward resurfaced patella. Smith et $\mathrm{al}^{77}$ evaluated 164 patients through KSS, reoperation rate, AKP, and patient's satisfaction. No significant differences have been revealed, but a lower AKP was reported for TKAs with resurfaced patella. ${ }^{77}$

Several other elements have gained importance for the assessment of the PFJ. Abnormal postoperative PF tracking has been described as linked to retropatellar pressure. ${ }^{78}$ However, some studies did not find a clear association between patellar tilt or subluxation and AKP. ${ }^{79}$

Generally, in the past, physicians believed that patellar height was linked to AKP. Patella baja, although it has a poor incidence in TKA, is surely a predisposing factor for flexion deficit, but there are no studies that correlated this condition to AKP. On the contrary, patella alta is generally associated with higher contact forces between the trochlea and patella. However, studies have not confirmed that it is a certain predisposing factor for developing AKP. ${ }^{80}$ van Houten et al ${ }^{80}$ analyzed the effects of patella positioning on AKP in TKA. The authors found that the amount of patellar displacement or patellar tilt is not related to AKP.

Another critical aspect that is generally discussed is the type of bearing surface of TKA. Fixed bearing has been always believed to be of higher risk compared with mobile bearing designs. Type of bearing surface might influence patellar kinematics, because some studies showed lower PF contact stress in the mobile bearing compared with fixed bearing. ${ }^{81}$ However, few studies demonstrated a potential benefit of mobile bearing in AKP, some of those suggested that the performances of mobile bearing decline over time. ${ }^{82-85}$

The tibiofemoral contact point is another potential predisposing factor for AKP. Greater anterior positioning of the tibiofemoral contact point is the complication of the lever arm of the extensor mechanism, which leads to PF disadvantage. ${ }^{86}$

The last important element that is able to create a variability in the onset of AKP is the vascular supply to the patella. In fact, the amount of resection of fat pad can play an important role. $^{87,88}$

\section{Conclusion}

The overall incidence of postoperative anterior knee in TKA is still too high. Evidence-based publications cannot be easily interpreted. There is statistical heterogeneity, perhaps because of methodological diversity. The general trends seem to present a reduction of risk of reoperation in TKA with a resurfaced patella, but without significant benefits to knee function and satisfaction with respect to patelloplasty. 
So the decision of whether or not to resurface the patella should be assessed according to the evaluation of the PF joint, the design of the prosthesis, the experience of the surgeons, and patient's features. ${ }^{89,90}$ Anyway, treatment of the patella does not seem to be the only factor that can influence AKP in TKA. Positioning of the femoral and tibial components, both in rotation and in AP direction, can influence the contact forces in the third space. The design of the prosthesis and choice of implant may also play an important role.

Treatment of smooth tissues is still poorly considered as a predisposing factor for AKP, such as the treatment of patellar fat pad, treatment of retinacula, and balancing of peripheral compartments could be extremely important both for vascular supply of the extensor mechanism and for biomechanical tracking of the third space.

\section{Conflict of Interest}

None declared.

\section{References}

1 McAlindon T, Zhang Y, Hannan M, et al. Are risk factors for patellofemoral and tibiofemoral knee osteoarthritis different? J Rheumatol 1996;23(02):332-337

2 Swan JD, Stoney JD, Lim K, Dowsey MM, Choong PF. The need for patellar resurfacing in total knee arthroplasty: a literature review. ANZ J Surg 2010;80(04):223-233

3 Sanchis-Alfonso V, Rosello-Sastre E, Martinez-Sanjuan V. Pathogenesis of anterior knee pain syndrome and functional patellofemoral instability in the active young. Am J Knee Surg 1999;12(01):29-40

4 Grabiner MD, Koh TJ, Draganich LF. Neuromechanics of the patellofemoral joint. Med Sci Sports Exerc 1994;26(01):10-21

5 Jerosch J, Prymka M. Knee joint proprioception in patients with posttraumatic recurrent patella dislocation. Knee Surg Sports Traumatol Arthrosc 1996;4(01):14-18

6 Ishikawa H, Sakurai A, Hirata S, et al. Painful bipartite patella in young athletes. The diagnostic value of skyline views taken in squatting position and the results of surgical excision. Clin Orthop Relat Res 1994;(305):223-228

7 Perrini F, Tallents RH, Katzberg RW, Ribeiro RF, Kyrkanides S, Moss ME. Generalized joint laxity and temporomandibular disorders. J Orofac Pain 1997;11(03):215-221

8 Duri ZA, Aichroth PM, Dowd G. The fat pad. Clinical observations. Am J Knee Surg 1996;9(02):55-66

9 Milgrom C, Finestone A, Eldad A, Shlamkovitch N. Patellofemoral pain caused by overactivity. A prospective study of risk factors in infantry recruits. J Bone Joint Surg Am 1991;73(07):1041-1043

10 Huberti $\mathrm{HH}$, Hayes WC. Patellofemoral contact pressures. The influence of q-angle and tendofemoral contact. J Bone Joint Surg Am 1984;66(05):715-724

11 Laughlin RT, Werries BA, Verhulst SJ, Hayes JM. Patellar tilt in total knee arthroplasty. Am J Orthop 1996;25(04):300-304

12 Shih HN, Shih LY, Wong YC, Hsu RW. Long-term changes of the nonresurfaced patella after total knee arthroplasty. J Bone Joint Surg Am 2004;86-A(05):935-939

13 Patel K, Raut V. Patella in total knee arthroplasty: to resurface or not to-a cohort study of staged bilateral total knee arthroplasty. Int Orthop 2011;35(03):349-353

14 Lybäck CO, Lehto MU, Hämäläinen MM, Belt EA. Patellar resurfacing reduces pain after TKA for juvenile rheumatoid arthritis. Clin Orthop Relat Res 2004;(423):152-156

15 Waters TS, Bentley G. Patellar resurfacing in total knee arthroplasty. A prospective, randomized study. J Bone Joint Surg Am 2003;85-A(02):212-217
16 Tabutin J, Banon F, Catonne Y, Grobost J, Tessier JL, Tillie B. Should we resurface the patella in total knee replacement? Experience with the Nex Gen prosthesis. Knee Surg Sports Traumatol Arthrosc 2005;13(07):534-538

17 Oh IS, Kim MK, You DS, Kang SB, Lee KH. Total knee arthroplasty without patellar resurfacing. Int Orthop 2006;30(05):415-419

18 Oztürk A, Bilgen S, Atici T, Ozer O, Bilgen OF. The evaluation of patients undergoing total knee arthroplasty with or without patellar resurfacing [in Turkish]. Acta Orthop Traumatol Turc 2006;40(01):29-37

19 Hurson C, Kashir A, Flavin R, Kelly I. Routine patellar resurfacing using an inset patellar technique. Int Orthop 2010;34(07):955-958

20 Keblish PA, Varma AK, Greenwald AS. Patellar resurfacing or retention in total knee arthroplasty. A prospective study of patients with bilateral replacements. J Bone Joint Surg Br 1994; 76(06):930-937

21 Kim BS, Reitman RD, Schai PA, Scott RD. Selective patellar nonresurfacing in total knee arthroplasty. 10 year results. Clin Orthop Relat Res 1999;367(367):81-88

22 Cerciello S, Robin J, Lustig S, Maccauro G, Heyse TJ, Neyret P. The role of patelloplasty in total knee arthroplasty. Arch Orthop Trauma Surg 2016;136(11):1607-1613

23 Lombardi AV Jr, Engh GA, Volz RG, Albrigo JL, Brainard BJ. Fracture/ dissociation of the polyethylene in metal-backed patellar components in total knee arthroplasty. J Bone Joint Surg Am 1988;70 (05):675-679

24 Rosenberg AG, Andriacchi TP, Barden R, Galante JO. Patellar component failure in cementless total knee arthroplasty. Clin Orthop Relat Res 1988;(236):106-114

25 Rader CP, Löhr J, Wittmann R, Eulert J. Results of total knee arthroplasty with a metal-backed patellar component. A 6-year follow-up study. J Arthroplasty 1996;11(08):923-930

26 Levi N, Kofoed H. Early failure of metal-backed patellar arthroplasty. J Bone Joint Surg Br 1994;76(04):675

27 Hsu HP, Walker PS. Wear and deformation of patellar components in total knee arthroplasty. Clin Orthop Relat Res 1989;(246): 260-265

28 Buechel FF, Pappas MJ, Makris G. Evaluation of contact stress in metal-backed patellar replacements. A predictor of survivorship. Clin Orthop Relat Res 1991;(273):190-197

29 Reuben JD, McDonald CL, Woodard PL, Hennington LJ. Effect of patella thickness on patella strain following total knee arthroplasty. J Arthroplasty 1991;6(03):251-258

30 Theiss SM, Kitziger KJ, Lotke PS, Lotke PA. Component design affecting patellofemoral complications after total knee arthroplasty. Clin Orthop Relat Res 1996;(326):183-187

31 Yercan HS, Ait Si Selmi T, Neyret P. The treatment of patellofemoral osteoarthritis with partial lateral facetectomy. Clin Orthop Relat Res 2005;(436):14-19

32 Briard JL, Hungerford DS. Patellofemoral instability in total knee arthroplasty. J Arthroplasty 1989;4(Suppl):S87-S97

33 Kirk P, Rorabeck CH, Bourne RB, Burkart B, Nott L. Management of recurrent dislocation of the patella following total knee arthroplasty. J Arthroplasty 1992;7(03):229-233

34 Brick GW, Scott RD. The patellofemoral component of total knee arthroplasty. Clin Orthop Relat Res 1988;(231):163-178

35 Grace JN, Sim FH. Fracture of the patella after total knee arthroplasty. Clin Orthop Relat Res 1988;(230):168-175

36 Insall JN, Lachiewicz PF, Burstein AH. The posterior stabilized condylar prosthesis: a modification of the total condylar design. Two to four-year clinical experience. J Bone Joint Surg Am 1982;64 (09):1317-1323

37 Kayler DE, Lyttle D. Surgical interruption of patellar blood supply by total knee arthroplasty. Clin Orthop Relat Res 1988;(229): $221-227$

38 Hozack WJ, Rothman RH, Booth RE Jr, Balderston RA. The patellar clunk syndrome. A complication of posterior stabilized total knee arthroplasty. Clin Orthop Relat Res 1989;(241):203-208 
39 Goldberg VM, Figgie HE III, Inglis AE, et al. Patellar fracture type and prognosis in condylar total knee arthroplasty. Clin Orthop Relat Res 1988;(236):115-122

40 Berry DJ, Rand JA. Isolated patellar component revision of total knee arthroplasty. Clin Orthop Relat Res 1993;(286):110-115

41 Cadambi A, Engh GA. Use of a semitendinosus tendon autogenous graft for rupture of the patellar ligament after total knee arthroplasty. A report of seven cases. J Bone Joint Surg Am 1992;74(07):974-979

42 Emerson RH Jr, Head WC, Malinin TI. Reconstruction of patellar tendon rupture after total knee arthroplasty with an extensor mechanism allograft. Clin Orthop Relat Res 1990;(260):154-161

43 Chun KA, Ohashi K, Bennett DL, El-Khoury GY. Patellar fractures after total knee replacement. Am J Roentgenol 2005;185(03): 655-660

44 Bourne RB, Burnett RS. The consequences of not resurfacing the patella. Clin Orthop Relat Res 2004;(428):166-169

45 Barrack RL, Bertot AJ, Wolfe MW, Waldman DA, Milicic M, Myers L. Patellar resurfacing in total knee arthroplasty. A prospective, randomized, double-blind study with five to seven years of follow-up. J Bone Joint Surg Am 2001;83-A(09):1376-1381

46 Feller JA, Bartlett RJ, Lang DM. Patellar resurfacing versus retention in total knee arthroplasty. J Bone Joint Surg Br 1996;78(02): 226-228

47 Burnett RS, Haydon CM, Rorabeck CH, Bourne RB. Patella resurfacing versus nonresurfacing in total knee arthroplasty: results of a randomized controlled clinical trial at a minimum of 10 years' follow-up. Clin Orthop Relat Res 2004;(428):12-25

48 Meneghini RM. Should the patella be resurfaced in primary total knee arthroplasty? An evidence-based analysis. J Arthroplasty 2008;23(7, Suppl):11-14

49 Pakos EE, Ntzani EE, Trikalinos TA. Patellar resurfacing in total knee arthroplasty. A meta-analysis. J Bone Joint Surg Am 2005;87 (07):1438-1445

50 Parvizi J, Rapuri VR, Saleh KJ, Kuskowski MA, Sharkey PF, Mont MA. Failure to resurface the patella during total knee arthroplasty may result in more knee pain and secondary surgery. Clin Orthop Relat Res 2005;438(438):191-196

51 Nizard RS, Biau D, Porcher R, et al. A meta-analysis of patellar replacement in total knee arthroplasty. Clin Orthop Relat Res 2005;(432):196-203

52 Swedish Knee Arthroplasty Register. Annual Report 2004 Part I and Part II. Available at: http://www.myknee.se/pdf/101_skar2004engl. pdf. Accessed November 26, 2018

53 Australian Orthopaedic Association. National Joint Replacement Registry; 2007. Available at: https://aoanjrr.sahmri.com/. Accessed November 26, 2018

54 Calvisi V, Camillieri G, Lupparelli S. Resurfacing versus nonresurfacing the patella in total knee arthroplasty: a critical appraisal of the available evidence. Arch Orthop Trauma Surg 2009;129(09): $1261-1270$

55 Patil N, Lee K, Huddleston JI, Harris AH, Goodman SB. Patellar management in revision total knee arthroplasty: is patellar resurfacing a better option? J Arthroplasty 2010;25(04):589-593

56 Li S, Chen Y, Su W, Zhao J, He S, Luo X. Systematic review of patellar resurfacing in total knee arthroplasty. Int Orthop 2011;35(03): 305-316

57 Chen K, Li G, Fu D, Yuan C, Zhang Q, Cai Z. Patellar resurfacing versus nonresurfacing in total knee arthroplasty: a meta-analysis of randomised controlled trials. Int Orthop 2013;37(06):1075-1083

58 Boyd AD Jr, Ewald FC, Thomas WH, Poss R, Sledge CB. Long-term complications after total knee arthroplasty with or without resurfacing of the patella. J Bone Joint Surg Am 1993;75(05):674-681

59 Sun YQ, Yang B, Tong SL, Sun J, Zhu YC. Patelloplasty versus traditional total knee arthroplasty for osteoarthritis. Orthopedics 2012;35(03):e343-e348

60 Župan A, Snoj Ž, Antolič V, Pompe B. Better results with patelloplasty compared to traditional total knee arthroplasty. Int Orthop 2014;38(08):1621-1625
61 Li B, Bai L, Fu Y, Wang G, He M, Wang J. Comparison of clinical outcomes between patellar resurfacing and nonresurfacing in total knee arthroplasty: retrospective study of 130 cases. J Int Med Res 2012;40(05):1794-1803

62 Liu ZT, Fu PL, Wu HS, Zhu Y. Patellar reshaping versus resurfacing in total knee arthroplasty - results of a randomized prospective trial at a minimum of 7 years' follow-up. Knee 2012;19(03): 198-202

63 Hwang BH, Yang IH, Han CD. Comparison of patellar retention versus resurfacing in LCS mobile-bearing total knee arthroplasty. Knee Surg Sports Traumatol Arthrosc 2012;20(03): 524-531

64 Leichtle UG, Wünschel M, Leichtle $\mathrm{CI}$, et al. Increased patellofemoral pressure after TKA: an in vitro study. Knee Surg Sports Traumatol Arthrosc 2014;22(03):500-508

65 Heyse TJ, Becher C, Kron N, et al. Patellofemoral pressure after TKA in vitro: highly conforming vs. posterior stabilized inlays. Arch Orthop Trauma Surg 2010;130(02):191-196

66 Arnoldi CC, Lemperg K, Linderholm H. Intraosseous hypertension and pain in the knee. J Bone Joint Surg Br 1975;57(03):360-363

67 Lee GW, Lee SM, Jang SJ, Son JH. The efficacy of patellar decompression for improving anterior knee pain following total knee arthroplasty without patellar resurfacing. Arch Orthop Trauma Surg 2013;133(04):561-567

68 Tompkins M, Arendt EA. Complications in patellofemoral surgery. Sports Med Arthrosc Rev 2012;20(03):187-193

69 Rodriguez-Merchan EC. Regeneration of articular cartilage of the knee. Rheumatol Int 2013;33(04):837-845

70 Wojtys EM, Beaman DN, Glover RA, Janda D. Innervation of the human knee joint by substance-P fibers. Arthroscopy 1990;6(04): 254-263

71 Schneider U, Graf J, Thomsen M, Wenz W, Niethard FU. Das Hypertensionssyndrom der Patella-Nomenklatur, Diagnostik und Therapie. Z Orthop Ihre Grenzgeb 1997;135(01):70-75

72 Ertürk C, Altay MA, Işikan UE. Patelloplasty with patellar decompression to relieve anterior knee pain in total knee arthroplasty. Acta Orthop Traumatol Turc 2011;45(06):425-430

73 Breugem SJ, van Ooij B, Haverkamp D, Sierevelt IN, van Dijk CN. No difference in anterior knee pain between a fixed and a mobile posterior stabilized total knee arthroplasty after 7.9 years. Knee Surg Sports Traumatol Arthrosc 2014;22(03):509-516

74 Smith AJ, Lloyd DG, Wood DJ. A kinematic and kinetic analysis of walking after total knee arthroplasty with and without patellar resurfacing. Clin Biomech (Bristol, Avon) 2006;21(04):379-386

75 Myles CM, Rowe PJ, Nutton RW, Burnett R. The effect of patella resurfacing in total knee arthroplasty on functional range of movement measured by flexible electrogoniometry. Clin Biomech (Bristol, Avon) 2006;21(07):733-739

76 Campbell DG, Duncan WW, Ashworth M, et al. Patellar resurfacing in total knee replacement: a ten-year randomised prospective trial. J Bone Joint Surg Br 2006;88(06):734-739

77 Smith AJ, Wood DJ, Li MG. Total knee replacement with and without patellar resurfacing: a prospective, randomised trial using the profix total knee system. J Bone Joint Surg Br 2008;90(01):43-49

78 Petersen W, Rembitzki IV, Brüggemann GP, et al. Anterior knee pain after total knee arthroplasty: a narrative review. Int Orthop 2014;38(02):319-328

79 van Jonbergen HP, Reuver JM, Mutsaerts EL, Poolman RW. Determinants of anterior knee pain following total knee replacement: a systematic review. Knee Surg Sports Traumatol Arthrosc 2014;22 (03):478-499

80 van Houten $\mathrm{AH}$, Heesterbeek PJ, Wymenga AB. Patella position is not a determinant for anterior knee pain 10 years after balanced gap total knee arthroplasty. Knee Surg Sports Traumatol Arthrosc 2016;24(08):2656-2662

81 Skwara A, Tibesku CO, Ostermeier S, Stukenborg-Colsman C, Fuchs-Winkelmann S. Differences in patellofemoral contact stresses between mobile-bearing and fixed-bearing total knee 
arthroplasties: a dynamic in vitro measurement. Arch Orthop Trauma Surg 2009;129(07):901-907

82 Aglietti P, Baldini A, Buzzi R, Lup D, De Luca L. Comparison of mobile-bearing and fixed-bearing total knee arthroplasty: a prospective randomized study. J Arthroplasty 2005;20(02): 145-153

83 Breugem SJ, Sierevelt IN, Schafroth MU, Blankevoort L, Schaap GR, van Dijk CN. Less anterior knee pain with a mobile-bearing prosthesis compared with a fixed-bearing prosthesis. Clin Orthop Relat Res 2008;466(08):1959-1965

84 Smith H, Jan M, Mahomed NN, Davey JR, Gandhi R. Meta-analysis and systematic review of clinical outcomes comparing mobile bearing and fixed bearing total knee arthroplasty. J Arthroplasty 2011;26(08):1205-1213

85 Biau D, Mullins MM, Judet T, Piriou P. Mobile versus fixed-bearing total knee arthroplasty: mid-term comparative clinical results of 216 prostheses. Knee Surg Sports Traumatol Arthrosc 2006;14(10): 927-933
86 de Jong RJ, Heesterbeek PJ, Wymenga AB. A new measurement technique for the tibiofemoral contact point in normal knees and knees with TKR. Knee Surg Sports Traumatol Arthrosc 2010;18 (03):388-393

87 White L, Holyoak R, Sant J, Hartnell N, Mullan J. The effect of infrapatellar fat pad resection on outcomes post-total knee arthroplasty: a systematic review. Arch Orthop Trauma Surg 2016;136(05):701-708

88 Jawhar A, Sohoni S, Shah V, Scharf HP. Alteration of the patellar height following total knee arthroplasty. Arch Orthop Trauma Surg 2014;134(01):91-97

89 Tanzer M, McLean CA, Laxer E, Casey J, Ahmed AM. Effect of femoral component designs on the contact and tracking characteristics of the unresurfaced patella in total knee arthroplasty. Can J Surg 2001; 44(02):127-133

90 Haynes RB, Devereaux PJ, Guyatt GH. Clinical expertise in the era of evidence-based medicine and patient choice. ACP J Club 2002; 136(02):A11-A14 